\title{
PROBLEMATIZAÇÃO DOS RECURSOS HÍDRICOS SUPERFICIAIS DA BACIA HIDROGRÁFICA DO RIO AURÁ E SUBTERRÂNEOS DA BACIA HIDROGRÁFICA DO RIO BACANGA - MARANHÃO - BRASIL
}

\author{
Bruno Neves Martins $^{(\mathrm{a})}$, Jonas Jansen Mendes ${ }^{(\mathrm{b})}$, Regina Célia de Castro Pereira ${ }^{(\mathrm{C})}$
}

(a) Mestrando do Curso de Pós Graduação em Geografia PPGEO - Universidade Estadual do Maranhão -

UEMAjjonasjansenn@ hotmail.com.

(b) Mestrando do Curso de Pós Graduação em Geografia PPGEO - Universidade Estadual do Maranhão - UEMA.

(c) Professora Doutora do Departamento de História e Geografia da Universidade Estadual do Maranhão e Professora Titular do

Mestrado em Geografia da Universidade Estadual do Maranhão.

\section{EIXO: BACIAS HIDROGRÁFICAS E RECURSOS HÍDRICOS: ANÁLISE, PLANEJAMENTO E GESTÃO}

\begin{abstract}
Resumo
A crescente demanda por água tem ocasionado problemas aos recursos hídricos em todo estado do Maranhão. Em alguns casos, o uso indiscriminado desse recurso tem chegado até a seca total de rios e aquíferos subterrâneos. Lamentavelmente, grande parte da água extraída para as atividades humanas, de qualquer que seja a fonte, é utilizada de maneira muito ineficaz. O objetivo do trabalho é apontar medidas de gestão dos recursos hídricos, correlacionando as bases teóricas da geografia, metodologias de gestão e a problematização dos recursos hídricos na bacia hidrográfica do rio Aurá e Bacanga. O estudo utilizou-se de fontes secundárias, sendo validadas in loco, apoiando-se nos métodos hipotético-dedutivo, baseando na análise de dados adquiridos através de referências bibliográficas, cartográficas, fotográficas e de campo. Os resultados mostraram que ambas as bacias hidrográficas sofrem problemas de seca, decorrente, fundamentalmente, da associação entre a falta de planejamento do uso do solo, a partir do crescimento exagerado das demandas localizadas, além de uma inexistência de um sistema de gestão das águas.
\end{abstract}

Palavras-chave:Recursos hídricos, bacia hidrográfica.

\section{INTRODUÇÃO}

É indiscutível a importância da água para a manutenção da vida na terra. Diante desta situação, a humanidade tem como tarefa garantir o acesso a mesma, em quantidade e qualidade suficientes.Trata-se de uma tarefa complexa, perante a crescente demanda populacional mundial, estimada em mais7 bilhões de pessoas (ONU,2011), queexige a busca de novos mananciais superficiais e subterrâneos para suprir a demanda hídrica.

O contexto histórico que envolve a temática é de âmbito primordial e complexo, segundo Pires (2001),

ao se analisar as preocupações da humanidade com relação aos recursos hídricos, verifica-se que até o final do século XIX elas se restringiram, além do atendimento às primeiras necessidades da vida, ao seu em prego na navegação e de forma ainda limitada, à agricultura (Pires, 2001). 
No entanto, no século XXI, devido ao crescimento e desenvolvimento industrial iniciado a partir do século XX, proporcionou uma crescente demanda das atividades produtivas, acarretando na superexploração dos mananciais (superficiais e subterrâneos). Como consequência deste quadro, Pires (2001), afirma que:

Situações de escassez e poluição dos recursos hídricos tornaram-se mais frequentes entre diferentes usuários de água. Intervenções estruturais mais robustas a partir de obras de reservação, captação, purificação, transporte e distribuição de água, foram sendo utilizadas com bases em novas tecnologias, de modo a aumentar a oferta de água. Porém, tais intervenções não foram suficientes e tornou-se necessário gerenciar esta oferta e também racionalizar o consumo, por meio do planejamento e do aproveitamento dos recursos hídricos de forma mais global, integrada nos diferentes usos e eficiente, a partir do que se começou a chamar de Gestão de Recursos Hídricos. (Pires, 2001, p.79,80).

Neste sentido, o Brasil concentra $12 \%$ de toda água superficial do planeta, entretanto, sua distribuição no território não se apresenta de forma homogênea. Um perfeito exemplo disto é a região hidrográfica da Amazônia, que representa aproximadamente $81 \%$ da disponibilidade hídrica do país. Oposto à situação descrita, a região do semiárido brasileiro possui sério déficit hídrico, corroboradospelas elevadas temperaturas e baixa pluviosidade.

Os usos da água no paíssão variados, que acarreta na elevada demanda e conflitos.

Assim, com o objetivo de gerenciar os recursos hídricos do país e mitigar conflitos,o governo brasileiro desenvolveuna década 90 a Política Nacional dos Recursos Hídricos - Lei 9.433 de 1997 que cria o Sistema Nacional de Gerenciamento de Recursos Hídricos e Regulamenta o inciso XIX do art. 21 da Constituição Federal.

Dentre as regulamentações que a lei dispõe, destacam-se: a água é um bem de domínio público (Art. $1^{\circ}$; I); a água é um recurso natural limitado, dotado de valor econômico (Art. $1^{\circ}$; II); a gestão dos recursos hídricos deve sempre proporcionar o uso múltiplo das águas(Art. $1^{\circ}$; IV); a bacia hidrográfica é a unidade territorial para implementação da Política Nacional de recursos Hídricos e atuação do Sistema Nacional de gerenciamento de Recursos Hídricos (Art. $1^{\circ}$; V); a gestão dos recursos hídricos deve ser descentralizada e contar com a participação do Poder Público, dos usuários e das comunidades.

Não obstante ao exposto, a Geografia - considerando a sua totalidade - desenvolve papel substancial nesta iniciativa, uma vez que, o estudo regional é a mais completa expressão do método geográfico (CHRISTOFOLETTI, 1982).

Logo, objetiva-se com este artigo apontar medidas de gestão dos recursos hídricos, correlacionando as bases teóricas da geografia, metodologias de gestão e a problematização dos recursos hídricos nas baciashidrográficas do Aurá e Bacanga. 


\section{MATERIAL E MÉTODOS}

28 de Junho à 02 de Julho de 2017

Situada na porção setentrional do Estado do Maranhão, a Ilha do Maranhão, encontra-se demarcada pelas coordenadas geográficas: 2²9'36.24"S/ 44¹8'14.97"O; $2^{\circ} 24^{\prime} 32.83 " \mathrm{~S} / 4^{\circ} 1^{\prime} 56.31 " \mathrm{O} ; 2^{\circ} 41^{\prime} 49.02^{\prime \prime S} / 44^{\circ} 9^{\prime} 50.38^{\prime \prime O}$ e $2^{\circ} 45^{\prime} 46.49^{\prime \prime} \mathrm{S} / 44^{\circ} 21^{\prime} 18.17^{\prime \prime O}$, possui uma área de 1.412,26 km², tendo seus espaços distribuídos entre os municípios de São Luís $(834,78$ km²), São José de Ribamar $(388,37$ km²), Paço do Lumiar $(122,83$ km²) e Raposa $\left(66,28 \mathrm{~km}^{2}\right)$ (IBGE, 2010) conforme Figura 1.

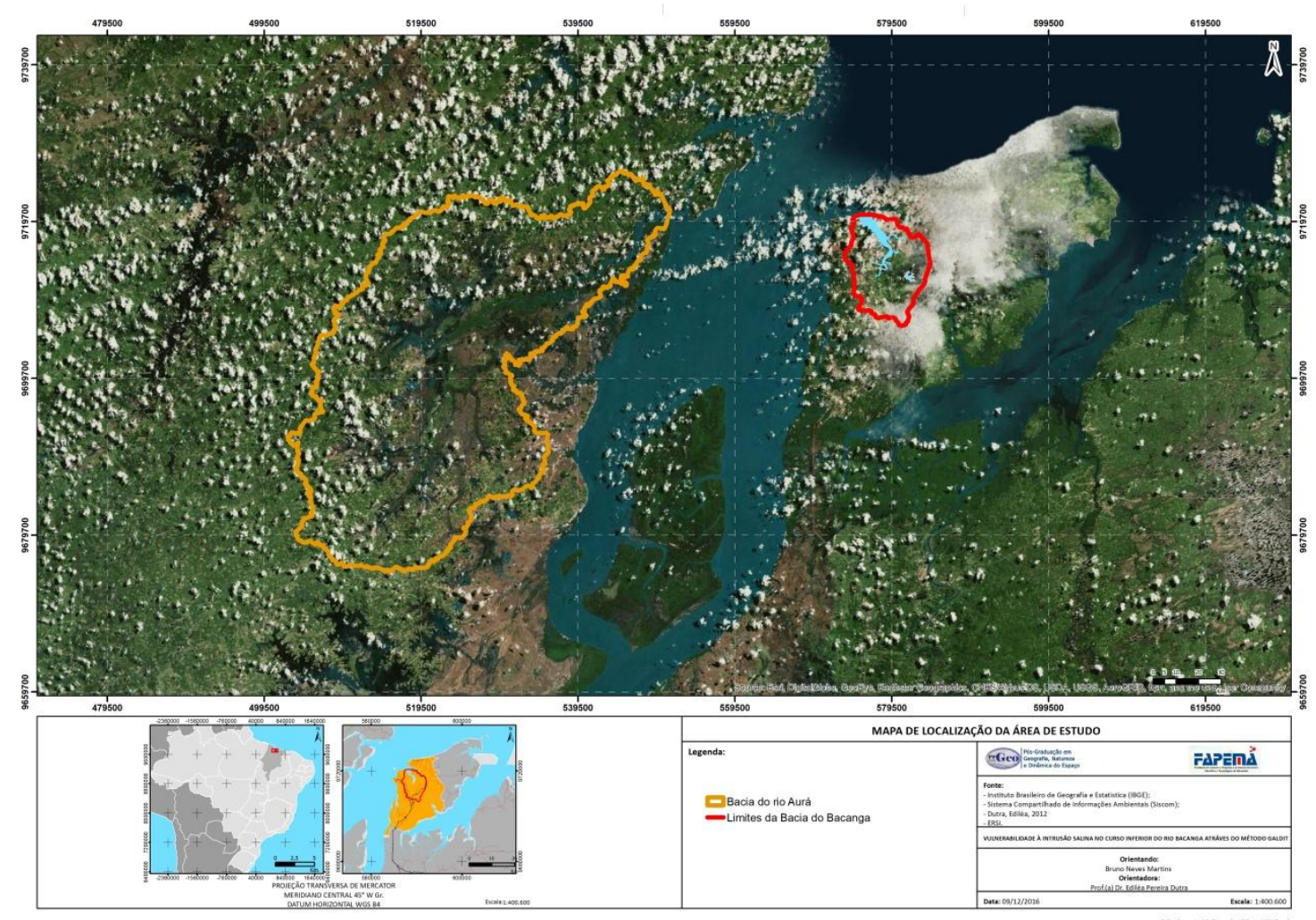

Figura 1 - Mapa de localização das áreas de estudo.

Fonte: Dados da Pesquisa.

Estima-se que a população residente nos quatro municípios, segundo último censo demográfico realizado em 2010, seja de 1.309,330 habitantes, destes 1.014,837 domiciliados em São Luís, 163.045 em São José de Ribamar, 105.121 em Paço do Lumiar e 26.327 habitantes em Raposa (IBGE, 2010).

Neste sentido, a bacia hidrográfica do Rio Bacanga, é a terceira maior bacia hidrográfica da ilha com uma estimativa de $56 \mathrm{~km}^{2}$. De acordo com Silva (2012), afirma que:

[...] as bacias hidrográficas da Ilha, quanto a sua dimensão areal em bacias grandes (Dimensão Areal superior a $100 \mathrm{~km}^{2}$ ), médias (Dimensão Areal entre 10 a $100 \mathrm{~km}^{2}$ ) e pequenas (Dimensão Areal inferior a $10 \mathrm{~km}^{2}$ ).

São classificadas como bacias grandes, em ordem decrescente, bacia do Paciência $\left(134,97 \mathrm{~km}^{2}\right)$, bacia do Tibiri $\left(106,15 \mathrm{~km}^{2}\right)$ e bacia do Bacanga $\left(104,38 \mathrm{~km}^{2}\right)$, bacias médias: Santo Antônio $(98,76$ km²), Cachorros $(62,99$ 
$\mathrm{km}^{2}$ ), Jeniparana $\left(48,98 \mathrm{~km}^{2}\right)$, Anil $\left(42,01 \mathrm{~km}^{2}\right)$, Tijupá $\left(24,68 \mathrm{~km}^{2}\right)$, Arapapar $\left(14,01 \mathrm{~km}^{2}\right)$, Jaguarema $\left(11,13 \mathrm{~km}^{2}\right)$ e Mosquitos $\left(10,90 \mathrm{~km}^{2}\right)$, as quais compõem o sistema hidrográfico das Ilhas Maranhenses [...].Silva (2012).

Já a Bacia hidrográfica do rio Aurá situada na porção norte do estado, possui aproximadamente 1.309,58 km², sendo constituída pelos municípios de São João Batista, São Vicente Ferrer, São Bento, Bacurituba, Palmeirândia, Peri-Mirim, Alcântara, Bequimão e Cajapió, constituinte da Área de Proteção Ambiental da Baixada Maranhense.

\section{Levantamento e análise bibliográfica e cartográfica}

Inicialmente, realizou-se uma pesquisa e seleção bibliográfica e cartográfica acerca de trabalhos relacionados à temática abordada. Aprofundou-se na literatura, buscando uma maior compreensão dos conceitos necessários para o desenvolvimento da pesquisa. As informações foram obtidas de livros, periódicos, resumos, dissertações, teses, artigos, manuais.

Segundo Demo (1994), afirma que o conhecimento teórico acarreta rigor, análise acurada, argumentação diversificada, desempenho logico, capacidade reflexiva sobre os paradigmas e as problemáticas acerca do objeto de estudo.

O material cartográfico utilizado consiste dos arquivos digitais georreferenciados no formato shapefile da delimitação da bacia hidrográfica do rio Bacanga, obtidos e disponibilizados por Pereira (2006), resultado da Tese intitulada Avaliação da vulnerabilidade natural à contaminação do solo e do aquífero do Reservatório Batatã-São Luís (MA).

Já os dados referentes à bacia hidrográfica do Auráforam realizados à partir da visita in loco e de cartas topográficas, oriundas do Shuttle Radar TopographyMission (SRTM), Banco de Dados Geomorfométricos do Brasil - TOPODATA e da Diretoria de Serviço Geográfico do Exército - DSG.

As demais informações referentes aos recursos hídricos foram extraídas de dados disponibilizados da Secretaria Estadual de Meio Ambiente - SEMA/MA, por meio da Superintendência de Recurso Hídricos - SRH.

\section{A relação entre o sujeito e o objeto}

O processo de construção de um modelo teórico-metodológico que considere todas as vertentes geográficas, com berço predominante no positivismo de Comte, correlacionada à pouca discussão teórica sobre o método, resultando em um pensamento científico cujo Spósito (2004), caracteriza em 3 métodos: o hipotético-dedutivo, em que se descreve o real através de 
hipóteses e deduções; o dialético, cujas relações contraditórias não precisam ser soberanas e as construções e as transformações sujeito/objeto são recíprocas e o fenomenológico, em que a sobreposição do sujeito ao objeto geram descrições do objeto a partir do ponto de vista do sujeito.

Segundo Foucault (1995), o sujeito é alguém que tem a consciência de que o conhecimento é algo que se produz através de interpretação que ele, sujeito, faz sobre as coisas; o objeto como fruto de interpretação, depende dos objetivos e da ótica de quem faz a pesquisa e sua representação.

Partindo do pressuposto que o ambiente seja objeto, para Whitehead (1993) deve ser entendido como o espaço em que a natureza humana vive e interage em sociedade, de modo harmônico ou conflituoso com a natureza (biótica e abiótica), sendo a natureza como tudo que se observa a partir da percepção obtida através dos sentidos.

Atualmente o que deve ser esperado dos geógrafos é a inter-relação do ambiente e sociedade (objeto e sujeito), edificando uma visão horizontal dos processos de produção da natureza, independente do recorte espacial considerado no estudo geográfico. Como um dos modelos dessa inter-relação, a gestão surge como uma prática que visa superar as lacunas causadas pela crise do planejamento, incorporando as relações de poder, a partir de um olhar da governabilidade superando as finalidades econômicas.

Considerando o espaço como o ambiente que detêm as propriedades básicas da sustentabilidade ambiental, levando como objeto os recursos hídricos, onde se torna necessário a construção de instrumentos que garanta modelos de gestão conciliável com a capacidade de suporte do recurso para as necessidades humanas e animal, assim como uma gestão participativa orientada para as comunidades e comprometimento dos gestores e empresa que balizam a gestão.

Desta forma, para esta pesquisa utilizou-se como método de investigação o hipotético-dedutivo, como caminhos para compreensão da situação hídrica das regiões em estudo.

\section{RESULTADOS E DISCUSSÃO}

\section{Panorama hídrico da bacia hidrográfica do Bacanga}

Devido ao crescimento populacional ascendente, a demanda por água consequentemente também é crescente, neste sentido, a Ilha, apresenta uma rede de drenagem 
significativa, composta por diversos rios e riachos de regime perene e intermitente, compondo um sistema de bacias e sub-bacias hidrográficas.

Entende-se como bacia hidrográfica ou bacia de drenagem como a área drenada por um determinado rio ou por um sistema fluvial (CHRISTOFOLETTI, 1980).

No entanto, problemas correlatos à temática "abastecimento hídrico" são recorrentes em sucessivos anos na capital do Estado, conforme noticiado em diversos veículos de comunicação (Figuras 2 e 3 ).

ÁGUA

Reservatório do Batatã opera com $20 \%$ da sua capacidade em pleno período chuvoso

1 JORNAL O ESTADO MA

(2) $15 / 05 / 2016$ às 00 h00

Figura 2 - Situação do principal reservatório de água que abastece o município de São Luís.

Fonte:Jornal O Estado MA, mai. 2016.

SÃo LUís

Rompimento da Italuís deixa 56 bairros sem água em São Luís

Imirante

() $12 / 01 / 2011$ às $17 \mathrm{~h} 29$

Figura 3 - Déficit do abastecimento hídrico a bairros da capital.

Fonte: Imirante, jan. 2011.

O abastecimento público de água potável no município de São Luís é efetuado pela Companhia de Saneamento Ambiental do Maranhão - CAEMA. Entretanto, a produção de água potável nos sistemas geridos pela CAEMA não conseguem atender a demanda exigida pela crescente população do município, o qual apresenta uma densidade demográfica de 1.215,69 $\mathrm{hab} / \mathrm{km}^{2}$ (IBGE, 2010).

De acordo com Pereira (2011), os quantitativos e contribuições para oabastecimento hídrico do município de São Luís estão divididos da seguinte forma, conforme Tabela 1: 
Tabela 1 - Demonstrativo dos sistemas de abastecimento e respectivas contribuições

\begin{tabular}{ccccc}
\hline Sistemas & $\begin{array}{c}\text { Água subterrânea } \\
\left(\mathbf{m}^{3}\right)\end{array}$ & $\begin{array}{c}\text { Água superficial } \\
\left(\mathbf{m}^{3}\right)\end{array}$ & Total $\left(\mathbf{m}^{3}\right)$ & $\%$ \\
\hline Sacavém & 505.703 & 1.138 .798 & $1.644,501$ & 17,2 \\
\hline Italuís & & 3.672 .208 & $3.672,208$ & 38,3 \\
\hline Paciência & 816.684 & - & 816.684 & 8,5 \\
\hline Sist. Isolados & 3.091 .352 & - & $3.091,352$ & 32,3 \\
\hline $\begin{array}{c}\text { Cidade } \\
\text { Operária }\end{array}$ & 353.023 & - & 353.023 & 3,7 \\
\hline Total & 4.766 .762 & 4.811 .006 & 9.577 .768 & 100 \\
\hline \multicolumn{5}{c}{ Fonte: Pereira, 2011. }
\end{tabular}

Verifica-se que apesar de apresentar uma disponibilidade hídrica superficial significativa, o abastecimento para fins de consumo humano, na Ilha, é predominantemente oriundo de mananciais subterrâneos, através da perfuração de poços tubulares.

As duas principais fontes superficiais de abastecimento hídrico da capital são: Primeira- Sistema Italuis - corresponde a 38\% da contribuição total, com ponto de captação no município de Santa Rita, no Rio Itapecuru, e uma vazão média de abastecimento de $3 \mathrm{~m} / \mathrm{s}$ (SEMA/SRH/2016); Segunda - a Represa do Batatã (Figura 4), a qual:

[... foi estrategicamente construída em 1964 pelo Departamento Nacional de Obras e Saneamento (DNOS) em uma área de cota altimétrica de 15 metros, área de acumulação de água, a partir dos tabuleiros de aproximadamente 60 metros. Tem comprimento de 485 metros e altura máxima de 17 metros o que possibilita uma acumulação de água de $4.600 .000 \mathrm{~m}^{3}$. A captação de água do reservatório instalada tem capacidade para retirar até 283 litros/segundo no período chuvoso, e em média 52,5 litros/segundo na estiagem...] (CAEMA, 2010apud

Pereira,2011).

Apesar de ambas as fontes apresentarem papel singular para a segurança hídrica da capital, ambas sofrem significativas intervenções humanas (assoreamento, desmatamento de matas galerias, irrigação, compactação do solo, represamento, extração de areia em leitos) o que diminui e até mesmo inviabiliza a captação de água para o abastecimento da população. 


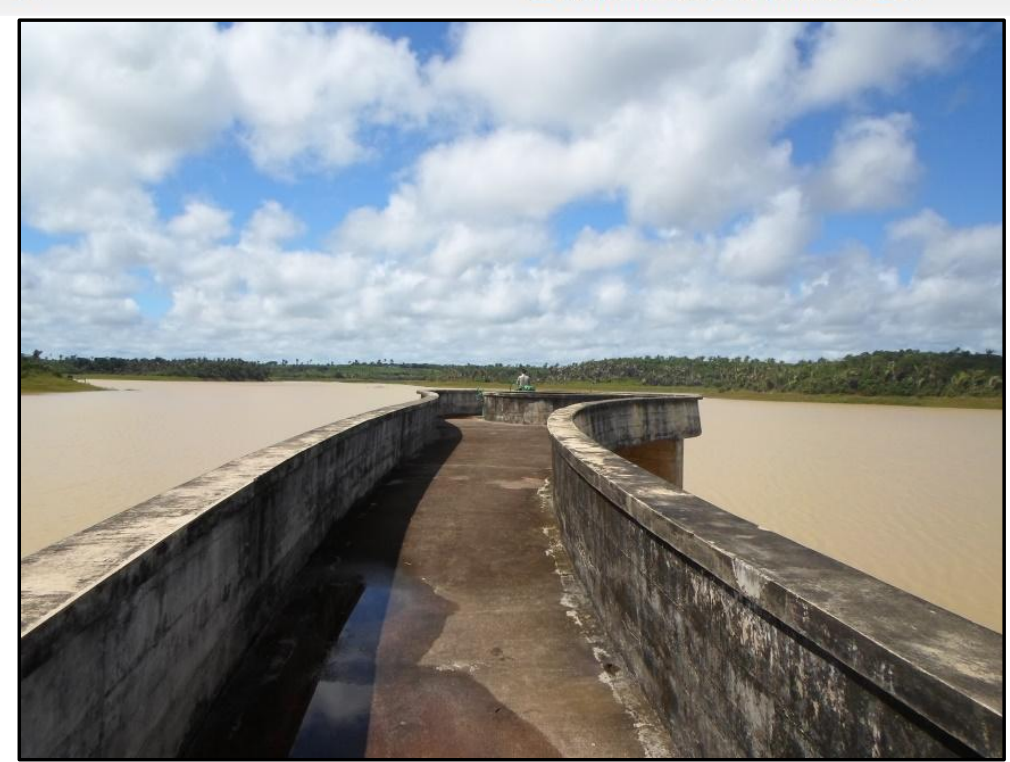

Figura 4 - Vista da Represa do Batatã

Fonte: Martins, 2013.

Diante de tal problemática, a alternativa adotada pela sociedade para suprir a demanda hídrica é a perfuração de poços tubulares. Segundo a CPRM, no ano de 2010, a quantidade de poços perfurados no Maranhão, distribuídos entre artesianos e cacimbas, outorgados e cadastrados no SIAGAS - Sistema de Informação de Água Subterrâneas, no ano de 2010, representava um quantitativo de 11.618 poços (Figura 5), destes mais de100 estão localizados na bacia hidrográfica do Bacanga, os quais estão devidamente outorgados pela Secretaria Estadual de Meio Ambiente - SEMA/MA.

No entanto, o que desperta preocupação esta relacionadoà possibilidade de superexplotação dos mananciais subterrâneos (aquíferos),em razão do risco de rebaixamento insustentável da superfície potenciométrica das águas subterrâneas, como pelo risco potencial sobre a qualidade das águas subterrâneas, em áreas sujeitas à intrusão salina, agravada pela elevação do nível do mar.

Assim, os sistemas de gestão se apresentam como ferramenta insubstituível, para que se possa atender as necessidades da população, as atividades econômicas e os interesses dominantes resultantes dos conflitos entre usuários (PIRES,2001). 


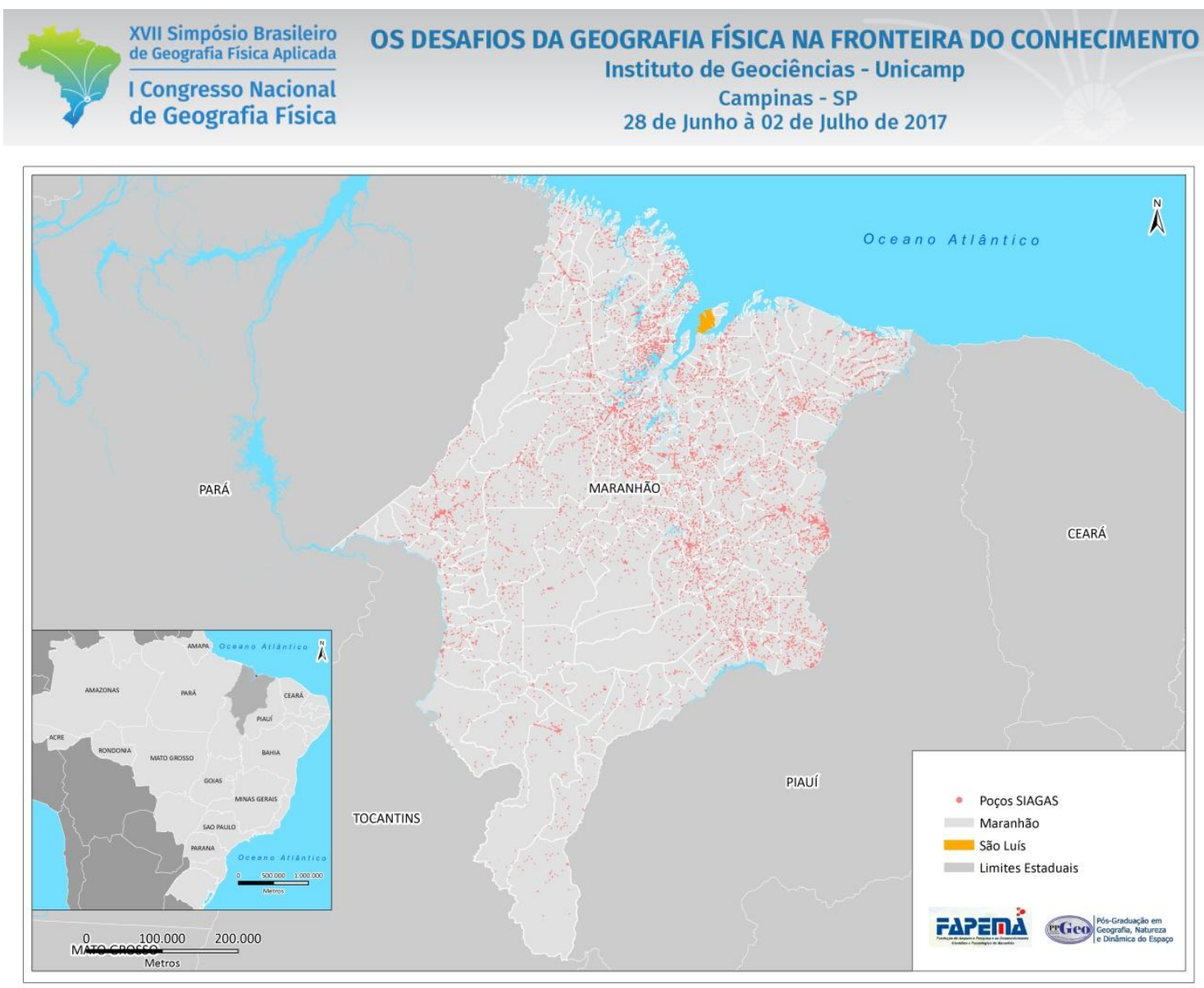

Figura 5 - Mapa de distribuição dos poços perfurados no Estado do Maranhão cadastrados no SIAGAS até o ano de 2010.

Fonte: Própria pesquisa.

Como um subconjunto de normas e leis, no estado do Maranhão, foram criada a

Lei 8.144/2004 - Política Estadual de Recursos Hídricos e os Decretos 27.845/2012 (Regulamenta - Águas Superficiais) e 28.008/2011 (Regulamenta - Águas Subterrâneas) que visam regulamentar e regimentar os usos,os conflitos pela água.

\section{Panorama hídrico da bacia hidrográfica do Aurá}

A referida bacia hidrográfica por estar genuinamente situada na Área de Proteção Ambiental da Baixada Maranhense, apresenta uma rica biodiversidade e favorece os diversos usos múltiplos da água, seja para recreação, pesca, abastecimento humano, transporte ou agricultura.

Atualmente a região apresenta poucas pesquisas, voltadas para compreensão do regime hídrico, porém segundo a Agência Nacional de Águas - ANA, a partir do monitoramento de secas, a região encontra-se no mês de outubro de 2016 em estágio de seca grave, em uma região que a média pluviométrica anual varia de 1600 a $2000 \mathrm{~mm}$, de acordo com o Núcleo Geoambiental - NUGEO/UEMA,(2002). 
A bacia hidrográfica do rio Aurá, em seu alto curso (Figura 6), situa os municípios de São João Batista, São Vicente Ferrer, Cajapió e São Bento apresentando uma lâmina d'água suficiente para as atividades de piscicultura e consumo humano, sendo realizado como forma de manter esse recurso, dragagem no leito do rio e barramentos, construídos pela colaboração entre o sindicato de pescadores e gestão municipal.

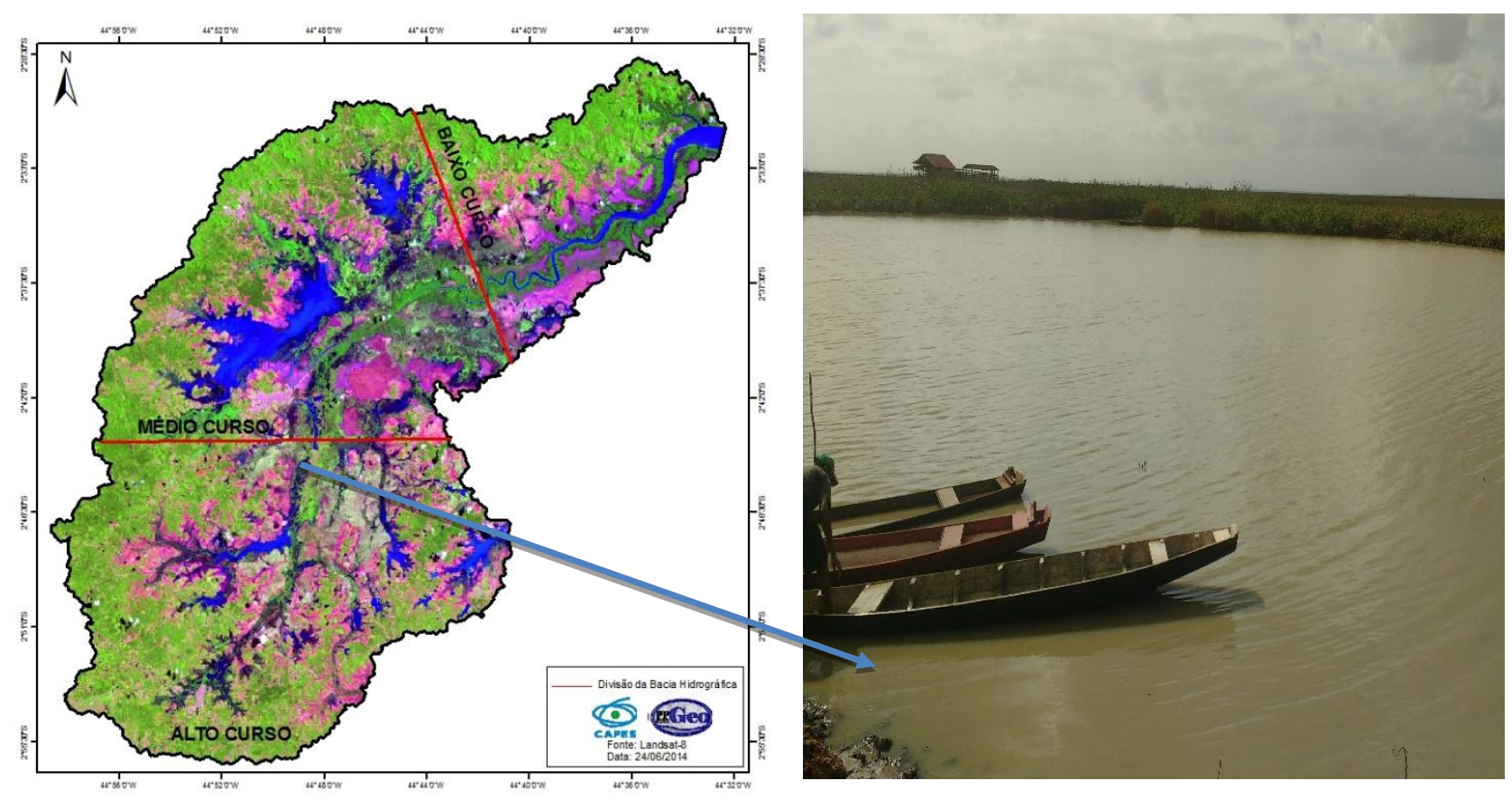

Figura 6. Região do Alto curso do rio Aurá

Fonte: Dados da pesquisa

De acordo com o Ministério da Integração Nacional (2002), as barragens são qualquer obstrução em um curso permanente ou temporário de água, para fins de retenção ou acumulação de substâncias líquidas ou misturas de líquidos e sólidos, compreendendo a estrutura do barramento, suas estruturas associadas e o reservatório formado pela acumulação.

O Médio curso do rio é configurado por diversas barragens com o escopo de represamento e acúmulo da água para suas diversas funções, tendo em vista que o conjunto de barramentos e a criação de açudes são medidas para minimizar os problemas da seca na região que tende agravar a cada ano (Figura 7). 


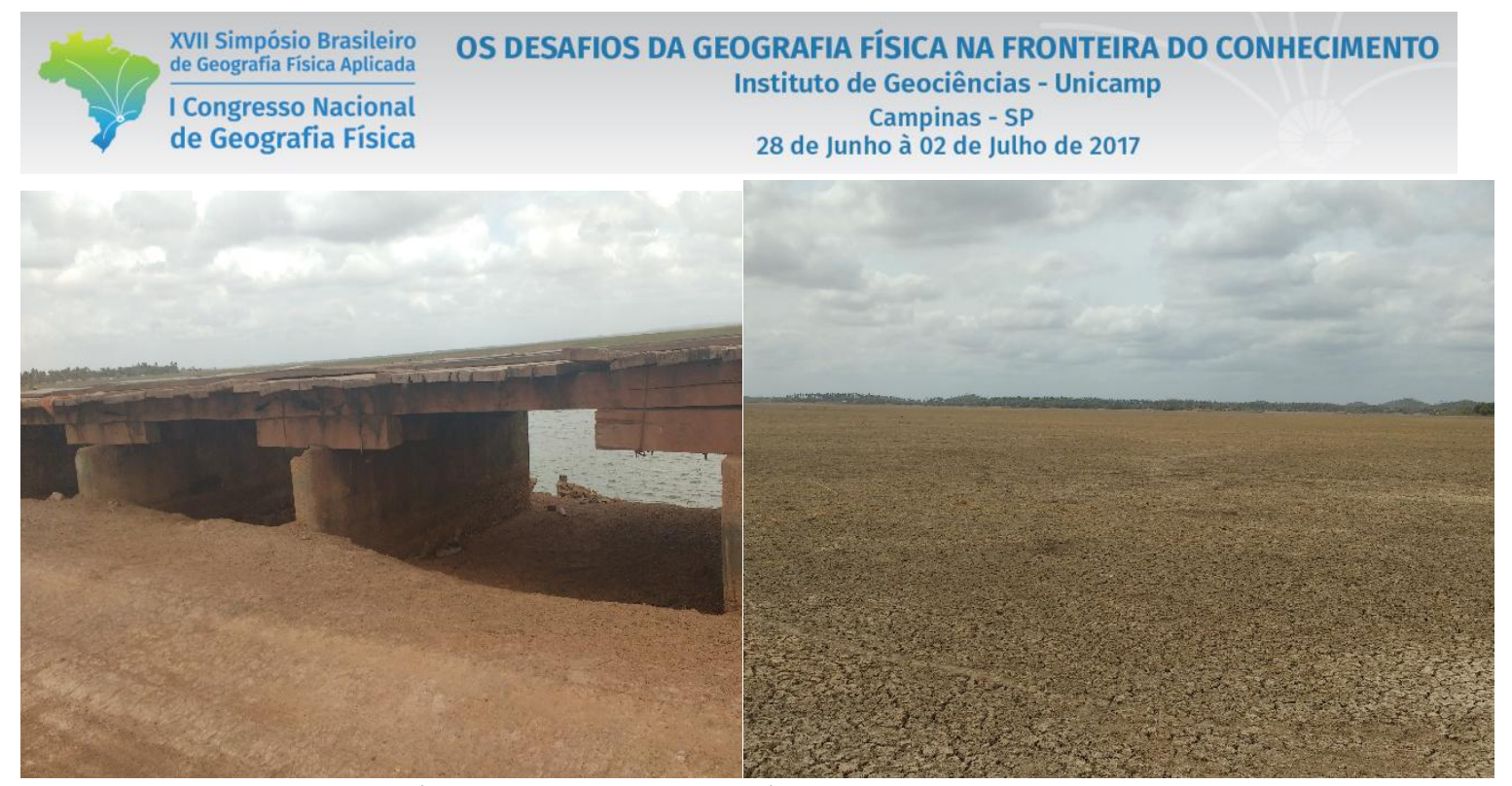

Figura 7. Médio curso do Rio Aurá - Barramentos e Secas graves

Fonte: Dados da pesquisa

A construção dessas estruturas artificiais, muita das vezes projetadas de forma irregular e sem as devidas licenças dos órgãos ambientais, configuram como um dos grandes protagonistas desse tipo de situação na região que situam os municípios de Palmeirândia, Bacurituba, Peri-Mirim e Bequimão.

Devido esse grande impacto social e ambiental, a gestão municipal realiza a construção de açudes, como forma de armazenar o recurso hídrico no período chuvoso para a dessedentação animal e perfuração de poços para abastecimento humano, refletindo na economia local com a diminuição da pecuária e piscicultura.

O baixo curso do rio Aurá configura como região de poucas habitações, situado no sul do município de Alcântara com grandes áreas de manguezais. No período de estiagem, devido o curso natural não desaguar na Baía de São Marcos, recebe a contribuição marinha e no período chuvoso, devido a vazão do rio se tornar maior o rio volta ao curso natural.

\section{CONCLUSÕES}

A ciência geográfica apresenta uma contribuição singular no estudo dos recursos hídricos superficiais e subterrâneos, avaliando as formas como o sujeito se apropria do bem natural e o comportamento desses recursos como meio para produção do espaço. Os problemas hídricos nas bacias hidrográficas em estudos decorrem, fundamentalmente, da associação entre a falta de planejamento do uso do solo, a partir do crescimento exagerado das demandas localizadas, além de uma inexistência de um sistema de gestão das águas. As condições de acesso aos recursos hídricos se dão através de uma gestão integrada e participativa, a partir de um planejamento organizado que visa o atendimento das demandas de água, considerando a 
disponibilidade restrita desse recurso, admitindo os instrumentos de outorga do direito de uso, o controle e a fiscalização nas referidas bacias hidrográficas.

\section{REFERÊNCIAS}

AGÊNCIA NACIONAL DE ÁGUAS. Disponível em:http://www2.ana.gov.br/Paginas/institucional/SobreaAna/planejamentoRH.aspx. Acesso em: 20 nov. 2016.

CHRISTOFOLETTI, Antônio. As Perspectivas dos Estudos Geográficos. Ed. DIFEL. São Paulo. 1982. . Geomorfologia, 2 ed., São Paulo: Edgar Blucher, 1980, 188 p.

INSTITUTO BRASILEIRO DE GEOGRAFIA E ESTATÍSTICA. Disponível em: http.www.ibge.gov.br. Acesso em: 20 mar.2016.

MAGRINI, Alessandra; SANTOS, Marco Aurélio dos. Gestão ambiental de bacias hidrográficas. Rio de Janeiro: UFRJ; COPPE; Instituto Virtual Internacional de Mudanças Globais; 2001.

MARTINS, Bruno Neves; PINHEIRO, Karina Suzana Feitosa. Construção dos Mapas hidrodinâmicos e de Vulnerabilidade das Águas Subterrâneas do Parque Estadual do Bacanga.São Luís - MA. IC. UEMA. 2013.

MINISTÉRIO DA INTEGRAÇÃO NACIONAL. Manual de Segurança e Inspeção de Barragens. Brasília: Ministério da Integração Nacional, 2002. 148p.

POLITICA NACIONAL DE RECURSOS HÍDRICOS. Disponível em: http://www.planalto.gov.br/ccivil_03/Leis/L9433.htm. Acesso em: 20 nov. 2016.

NUGEO/LABGEO. Atlas do Estado do Maranhão. UEMA. 2ed. São Luís/MA. 2002.

O ESTADO DO MARANHÃO. Disponível em: www.imirante.com. Acesso em: 22 nov. 2016

PEREIRA, E. D.; JUNIOR, F. A. C.; COSTA, H.de O.S.; CASTRO, M.D.F. Reservatório Batatã: Importância Hídrica e Conflitos de uso e ocupação no município de São Luís, Maranhão/Brasil: Revista Geográfica da américa Central, 2011.

PEREIRA, Edilea Dutra. Avaliação da vulnerabilidade natural à contaminação do solo e do aqüífero do Reservatório Batatã-São Luís (MA). Tese (Doutorado em Geociências)- Universidade Estadual Paulista - UNESP. Presidente Prudente. 2006. 